\title{
Synthesis and Preliminary Properties of Novel Poly(aryl ether)s Containing $\beta$-Naphthalene Pendant Group
}

\author{
L. Wang, D. Tao, X. Z. Xiang, and G. M. Zhu \\ Shenzhen Key Laboratory of Special Functional Materials and College of Materials Science and Engineering, \\ Shenzhen University, Shenzhen 518060, China
}

Correspondence should be addressed to L. Wang; wl@szu.edu.cn

Received 29 May 2014; Accepted 14 July 2014; Published 28 August 2014

Academic Editor: Waqar Ahmad

Copyright (c) 2014 L. Wang et al. This is an open access article distributed under the Creative Commons Attribution License, which permits unrestricted use, distribution, and reproduction in any medium, provided the original work is properly cited.

Two novel poly(aryl ether)s containing $\beta$-naphthalene pendant group were synthesized and the structures of these polymers were confirmed by ${ }^{1} \mathrm{HNMR}$ spectroscopy. The polymers exhibited good thermal stabilities with high $T_{g}$ of $256^{\circ} \mathrm{C}$ and $274^{\circ} \mathrm{C}$, respectively. The polymers are soluble in common organic solvents, such as DMAc, DMSO, $\mathrm{CH}_{2} \mathrm{Cl}_{2}$, and $\mathrm{CHCl}_{3}$, and can be electrospun into microfiber $(1-5 \mu \mathrm{m})$ with lots of nanopores $(<100 \mathrm{~nm})$ from $\mathrm{CHCl}_{3}$ solution. These fibers showed high hydrophobicity, and the contact angle of fibers is above $120^{\circ}$.

\section{Introduction}

Poly(aryl ether)s [1-10] have extensive applications in aerospace, aviation, electronics, telecommunications, nuclear energy, and other high technology fields because of their excellent properties, such as heat resistance, radiation resistance, impact resistance, and chemical resistance. Poly(aryl ether ketone)s (PAEKs) and poly(aryl ether sulfone)s (PAESs) are two important commercial poly(aryl ether)s. It is difficult for the standard PAEKs to be used as thin films and coating materials because of their semicrystalline property and poor solubility. For PAESs, their solvent resistance is often poor and they could not form oriented film or fiber [11, 12]. Therefore, study on improving the processing properties and solubility of poly(aryl ether)s through structural modification is one of the research hotspots. Structure changes have focused on the introduction of semi flexible groups (such as sulfone, sulfur ether, methylene substituents) to improve the solubility and rigid groups (such as naphthalene [12-14], aromatic heterocyclic, anthracene) to enhance the thermal stabilities, and the incorporation of pendant alkyl or phenyl groups on to the poly(aryl ether) in the backbone of the polymeric chain [15-19]. Our group has synthesized and characterized poly(aryl ether)s with pendant $\alpha$-naphthyl groups [20]. Recent study indicated that these polymers could be electrospun into microfiber with nanopores [12]. As we know that the properties of compounds substituted with $\alpha$-naphthalene and $\beta$-naphthalene are different, we think that if $\beta$-naphthyl groups are introduced into the poly(aryl ether) chain, the properties of the polymers may be enhanced. In order to further study poly(aryl ether)s with pendant naphthyl groups, two novel poly(aryl ether)s were synthesized by using bis(3,5-dimethyl-4-hydroxyphenyl)- $\beta$ naphthyl methane and $4,4^{\prime}$-difluorobenzophenone or bis(4fluorophenyl) sulfone through nucleophilic aromatic substitution. The thermal stabilities and solubility were investigated. In addition, these polymers could be made into fibers and the morphologies of the fibers were also characterized.

\section{Experimental Section}

2.1. Materials. Bis(3,5-dimethyl-4-hydroxyphenyl)- $\beta$-naphthyl methane, 4,4'-difluorobenzophenone, bis(4-fluorophenyl) sulfone, 3-mercaptopropionic acid, and sulfuric acid (60\%) were purchased from commercial sources and used as received. Toluene was dried with sodium wire and DMAC was dried with $4 \AA$ molecule sieves prior to use. Anhydrous potassium carbonate was dried at $300^{\circ} \mathrm{C}$ for $24 \mathrm{~h}$ in furnace prior to use. 


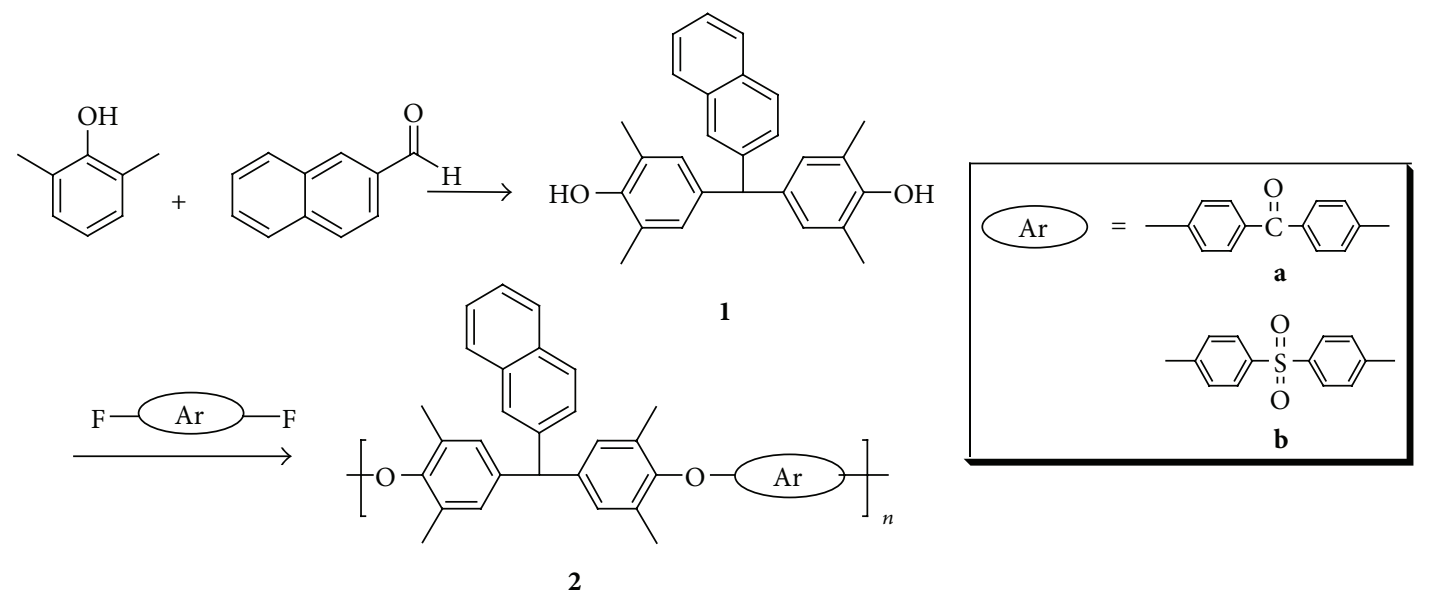

SCHeme 1: Syntheses of monomer 1 and polymers 2.

2.2. Characterization and Methods. ${ }^{1} \mathrm{H}-\mathrm{NMR}$ spectra, reported in ppm, were recorded on a Varian $400 \mathrm{~Hz}$ NMR instrument using DMSO- $\mathrm{d}_{6}$ or chloroform as the solvent and tetramethylsilane (TMS) as the internal standard. The thermal stability of the polymers was evaluated on a PerkinElmer TGA/DTA 6300 at a heating rate of $20^{\circ} \mathrm{C} / \mathrm{min}$ under nitrogen. A Perkin-Elmer DSC-7C calorimeter was used to measure the $T_{g}$ at a heating rate of $20^{\circ} \mathrm{C} / \mathrm{min}$ under nitrogen. The average molecular weights of the polymers were estimated by a Waters 510 HPLC gel permeation chromatography (GPC) system equipped with $5 \mu \mathrm{m}$ phenol gel columns (linear, $4 \times 500 \AA$ ) arranged in series using polystyrene as the standard. Microscopic surface morphology of polymer fiber was studied with a JEOL JSM-5610 scanning electron microscope (SEM). Water contact angles of the polymer films on a glass slide were measured with a 59980-35 contact angle analyzer from COLE-PARMER. Melting points were taken on a XT4A melting point apparatus.

2.3. Syntheses of Monomer 1 and Polymers 2. As depicted in Scheme 1, bis (3,5-dimethyl-4-hydroxy phenyl)-2-naphthyl methane (monomer 1) was synthesized. To a $100 \mathrm{~mL}$ threeneck round bottom flask, equipped with a reflux condenser, magnetic stirrer, nitrogeninlet, and a drop funnel, 2naphthaldehyde ( $15.6 \mathrm{~g}, 0.1 \mathrm{~mol}), 2,6$-dimethylphenol (36.6 g, $0.3 \mathrm{~mol}), 40 \mathrm{~mL}$ of toluene were introduced. A portion of $10 \mathrm{~mL}$ of $60 \mathrm{wt} \% \mathrm{H}_{2} \mathrm{SO}_{4}$ with 5 drops of 3 -mercaptopropionic acid was added dropwise at room temperature for $30 \mathrm{~min}$. The reaction mixture was heated at $50-55^{\circ} \mathrm{C}$, stirring for $12 \mathrm{~h}$, until the viscous pink precipitation was produced. The resulting mixture was washed with water 3 times and small amount of toluene 2 times and then recrystallized with toluene 2 times. Finally, we get light-yellow crystal. After filtration, the precipitation was dried at $30^{\circ} \mathrm{C}$ under vacuum for $24 \mathrm{~h}$. Melting point $\left(T_{m}\right)$ was $166-167^{\circ} \mathrm{C}$.

The structure of the monomer was confirmed by ${ }^{1} \mathrm{H}$ NMR spectra (Figure 1). ${ }^{1} \mathrm{HNMR}\left(\mathrm{DMSO}-\mathrm{d}_{6}, \delta \mathrm{ppm}\right): 2.102(\mathrm{~s}, 12 \mathrm{H})$, $5.399(\mathrm{~s}, 1 \mathrm{H}), 6.688(\mathrm{~s}, 4 \mathrm{H}), 7.295-7.299$ (d, 1H), 7.4467.512 (m, 3H), 7.743-7.845 (m, 3H), 8.097 (s, 2H). Elemental.

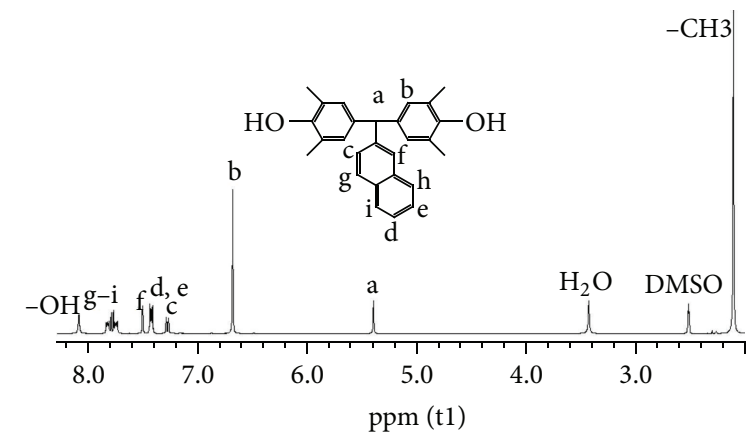

FIGURE 1: ${ }^{1} \mathrm{H}$ NMR spectrum of monomer 1 in DMSO- $\mathrm{d}_{6}$.

analysis: calculated for $\mathrm{C}_{27} \mathrm{H}_{26} \mathrm{O}_{2}$ (382.49): C, 84.78; $\mathrm{H}, 6.85$. Found: C, 84.67; H, 6.80.

The poly(aryl ether)s were prepared as depicted in Scheme 1. To a $25 \mathrm{~mL}$ three-neck round bottom flask equipped with a part flow arrangement and condenser under nitrogen. $4,4^{\prime}$-difluorobenzophenone $(0.218 \mathrm{~g}, 1.0 \mathrm{mmol})$ or bis(4-fluorophenyl) sulfone $(0.254 \mathrm{~g}, 1.0 \mathrm{mmol})$, bisphenol monomer $1(0.382 \mathrm{~g}, 1.0 \mathrm{mmol})$, anhydrous potassium carbonate $(0.208 \mathrm{~g}, 1.5 \mathrm{mmol})$, DMAc $(2.0 \mathrm{~mL})$, and toluene $(5 \mathrm{~mL})$ were carefully introduced. The reaction mixture was first heated at $140-150^{\circ} \mathrm{C}$ for $4 \mathrm{~h}$ to remove the water produced by azeotropic dissolution. Then the temperature was increased to $170-180^{\circ} \mathrm{C}$ and this temperature was kept for 2$3 \mathrm{~h}$. After it was cooled, the resulting mixture was diluted with $2 \mathrm{~mL}$ DMAc and poured into $100 \mathrm{~mL}$ methanol containing $2 \mathrm{~mL}$ of concentrated $\mathrm{HCl}$ slowly to precipitate white nodular solid. The white solid polymer was washed with methanol. After drying, the polymer was dissolved in $50 \mathrm{~mL}$ chloroform and filtered through a funnel. The filtrate was concentrated to about $7 \mathrm{~mL}$ and then added dropwise into $100 \mathrm{~mL}$ methanol to precipitate out the white polymer. After filtration, the precipitation was dried at $120^{\circ} \mathrm{C}$ under vacuum for $24 \mathrm{~h}$ (yield: $92 \%)$.

The structure of the polymers was confirmed by ${ }^{1} \mathrm{HNMR}$ spectra (Figure 2). ${ }^{1} \mathrm{HNMR}\left(\mathrm{CDCl}_{3}, \delta \mathrm{ppm}\right)$ : polymer 2a: 

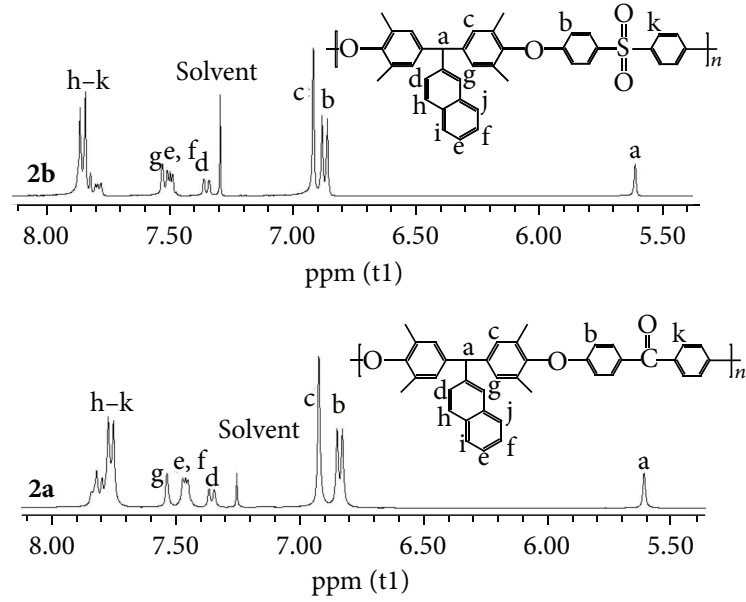

Figure 2: ${ }^{1} \mathrm{H}$ NMR spectrum of polymers 2 in $\mathrm{CDCl}_{3}$.

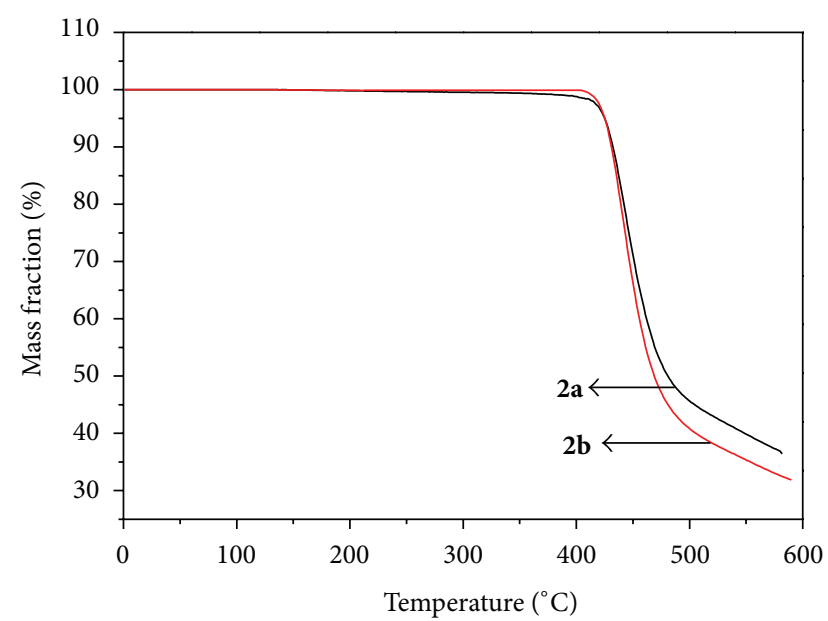

FIgURE 3: TGA curves of polymers 2.

$2.080(\mathrm{~s}, 12 \mathrm{H}), 5.608(\mathrm{~s}, 1 \mathrm{H}), 6.824-6.845(\mathrm{~m}, 4 \mathrm{H}), 6.919$ (s, $4 \mathrm{H}), 7.341-7.362$ (d, 1H), 7.446-7.467 (m, 2H), 7.531 (s, 1H), $7.746-7.768(\mathrm{~m}, 5 \mathrm{H}), 7.814(\mathrm{~m}, 2 \mathrm{H})$; polymer $2 \mathrm{~b}: 2.007(\mathrm{~s}, 12 \mathrm{H})$, 5.575 (s, 1H), 6.823-6.845 (m, 4H), 6.880 (s, 4H), 7.300-7.325 (d, 1H), 7.449-7.491 (m, 3H), 7.740-7.783 (m, 5H), 7.902-7.907 (m, 2H).

2.4. Electrospinning Setup. The condition of electrospinning at the room temperature was illustrated as follows: the polymers were dissolved in $\mathrm{CHCl}_{3}$ with a dissolvability of $7.5 \mathrm{wt} \%$ (polymer 2a) and $6 \mathrm{wt} \%$ (polymer $\mathbf{2 b}$ ), respectively. The solutions were placed in a syringe with metallic needle (inner tip diameter of $1 \mathrm{~mm}$ ) and a grounded aluminum sheet (thickness, $0.02 \mathrm{~mm}$ ) was used as the collector. The distance between the spinneret and collector plate was $15 \mathrm{~cm}$. The voltage was $30 \mathrm{kV}$. The ejection rate of the solution was $5 \mathrm{~mL} / \mathrm{h}$. The distance between the tip of the syringe (anode) and the surface of collector (cathode) was $15 \mathrm{~cm}$. The applied direct current voltage was $30 \mathrm{kV}$. The ejection rate
TABLE 1: Molecular weights and thermal properties of polymers.

\begin{tabular}{lcccc}
\hline Polymer & $M_{n}\left(\times 10^{4}\right)$ & $M_{w}\left(\times 10^{4}\right)$ & $T_{g}\left({ }^{\circ} \mathrm{C}\right)$ & $T_{5 \%}\left({ }^{\circ} \mathrm{C}\right)$ \\
\hline Polymer 2a & 8.7 & 16.2 & 256 & 418 \\
Polymer 2b & 7.8 & 13.5 & 274 & 424 \\
$\alpha$-Polymer a [20] & 9.6 & 24.4 & 252 & 417 \\
$\alpha$-Polymer b [20] & 8.9 & 24.3 & 273 & 447 \\
\hline
\end{tabular}

of the solution from the syringe was kept at $5 \mathrm{~mL} / \mathrm{h}$ and the electrospinning process was carried out in air.

\section{Results and Discussion}

3.1. Thermal Properties and Hydrophobicity. Thermal properties of the polymers were given in Table 1 and Figure 3. The polymers exhibited excellent thermal properties with $5 \%$ mass loss at $T>400^{\circ} \mathrm{C}$ and high $T_{g}$ of $T>250^{\circ} \mathrm{C}$. Compared to the results of the polymers containing $\alpha$-naphthalene groups [20], the $T_{g}$ slightly raised due to the introduction of $\beta$-naphthalene group. With the introduction of bulky $\beta$ naphthalene group in the polymer side chain, the chain segment movement steric hindrance increased, so that the $T_{g}$ of the polymer containing $\beta$-naphthalene group increased. The $T_{g}$ of the polymer $\mathbf{2 b}$ is significantly higher than that of polymer $2 \mathrm{a}$ due to the introduction of the sulfone group. Similar with the polymers containing $\alpha$-naphthalene groups, the polymers containing $\beta$-naphthalene group failed to show the melting points. This indicated they were amorphous in nature. The WAXD spectra showed a diffuse scattering peak from $12^{\circ}$ to $25^{\circ}$ with no crystallization peak and further confirmed the amorphous nature.

The contact angles both for water and glycerol on polymer films and fiber membranes were measured. The contact angles on both of the fiber membranes were about $120^{\circ}$ (part of the contact angles were shown in Figure 4), however, on the films only around $90^{\circ}$. It indicated that the hydrophobicity of poly(aryl ether)s was improved by electrospinning, because the surface free energy of fibers was much higher than that of films.

3.2. Solubility and Morphology. The polymers were soluble in common organic solvents, such as $\mathrm{CHCl}_{3}, \mathrm{CH}_{2} \mathrm{Cl}_{2}, \mathrm{THF}$, DMAc, and DMSO, and could be electrospun into microfiber with lots of nanopores. The scanning electron micrographs of polymers $\mathbf{2 a}$ and $\mathbf{2 b}$ fibers were shown in Figures 5 and 6 , respectively.

The SEM of the polymer fibers showed that the fibers were all ribbon-shaped, and the average diameters of polymers $\mathbf{2 a}$ and $\mathbf{2 b}$ fibers were about $1 \mu \mathrm{m}$ and $5 \mu \mathrm{m}$, respectively. These poly(aryl ether) fibers are not solid; there are a lot of pores, even the fibers are hollow. Moreover, there were lots of nanopores on the poly(aryl ether) fibers, and many nanopores are communicated with the internal. The nanopores were probably produced by the rapid evaporation of chloroform solvent. 


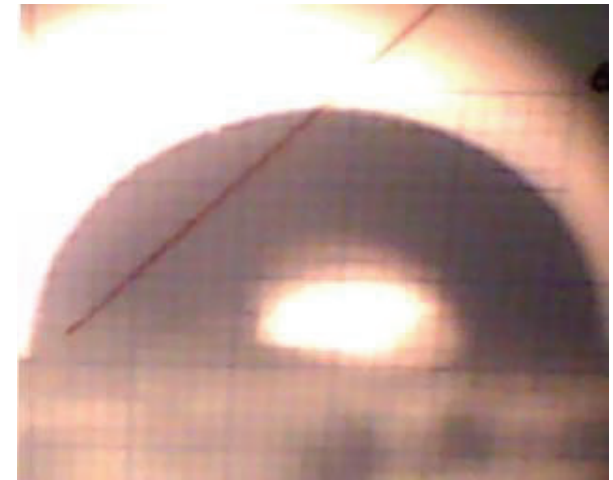

Water on film $\left(92^{\circ}\right)$

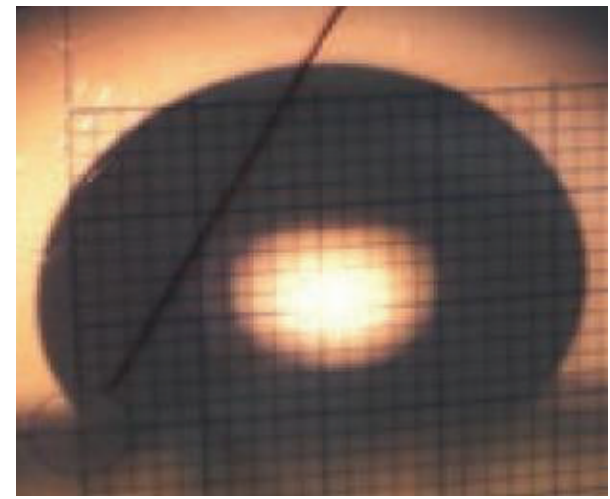

Water on fiber $\left(120^{\circ}\right)$

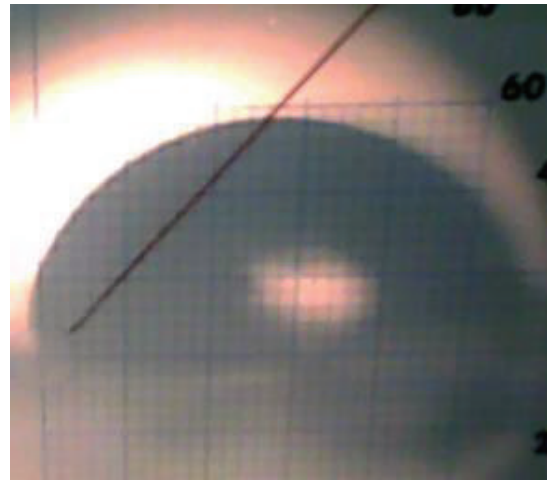

Glycerol on film $\left(96^{\circ}\right)$

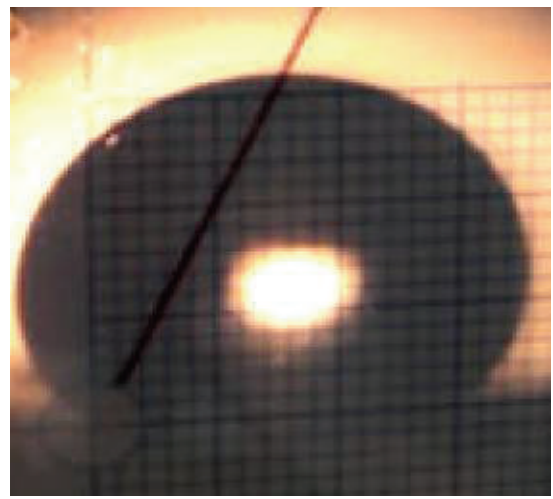

Glycerol on fiber $\left(128^{\circ}\right)$

FIgURE 4: The profiles of a droplet on the polymer 2 a surface.
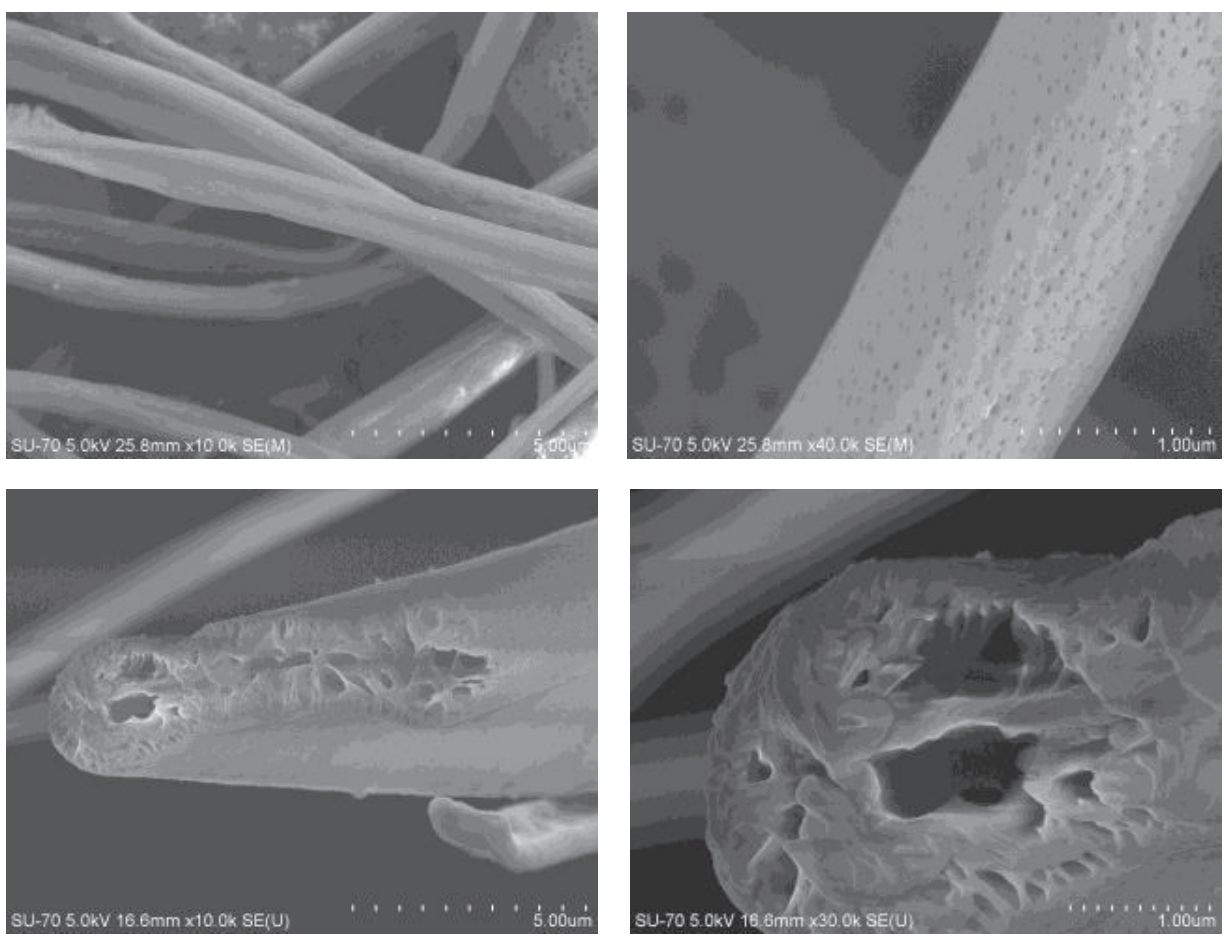

FIGURE 5: Scanning electron micrographs of polymer 2a fiber. 

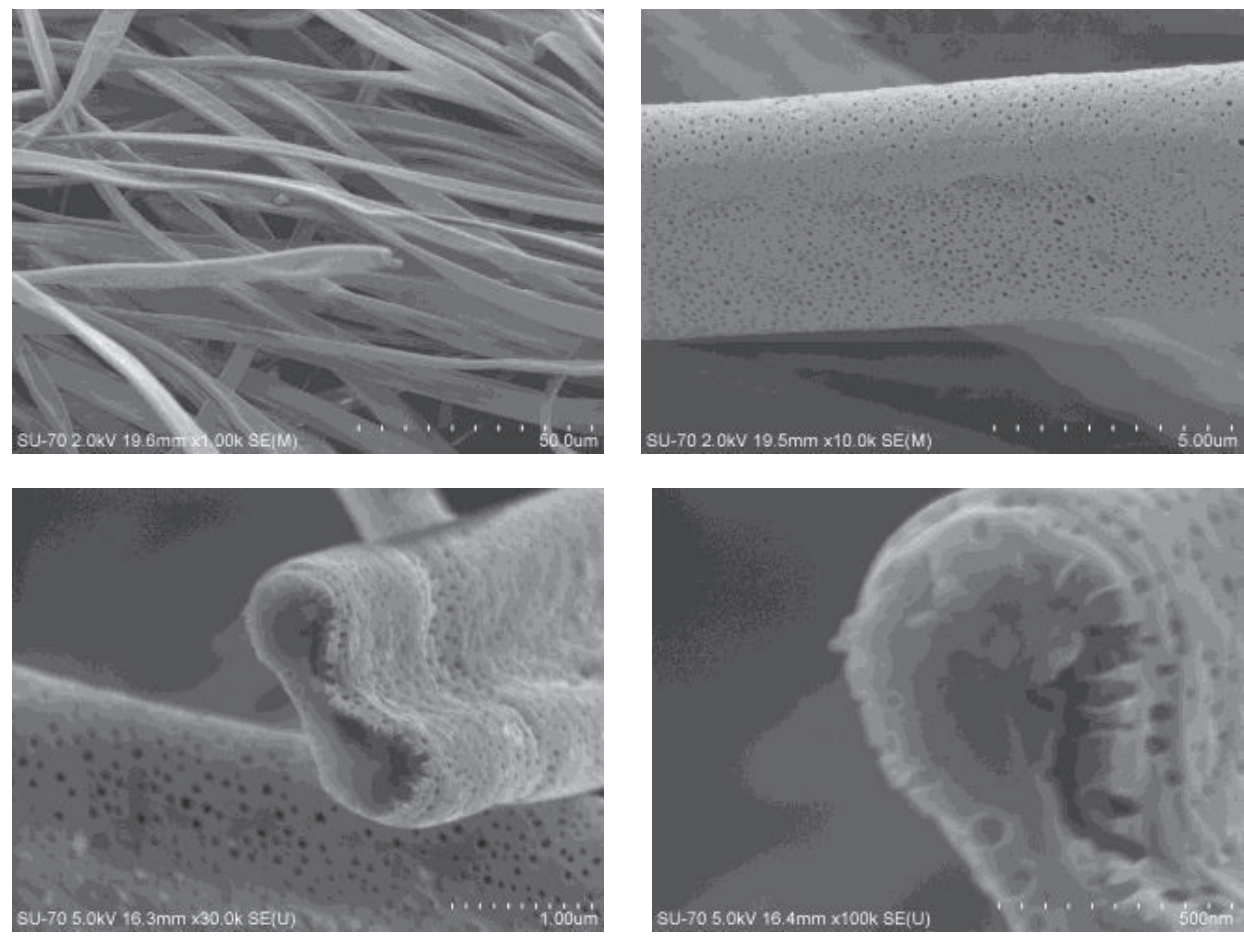

FIgURE 6: Scanning electron micrographs of polymer $\mathbf{2 b}$ fiber.

\section{Conclusion}

The novel poly(aryl ether)s containing $\beta$-naphthalene pendant group were successfully synthesized. These polymers had excellent thermal stabilities and good solubility. The fibers with many nanopores that were produced by electrospinning exhibited high hydrophobicity. The polymers could be potentially used as high temperature materials, waterproof materials, and transport carriers.

\section{Conflict of Interests}

The authors declare that there is no conflict of interests regarding the publication of this paper.

\section{Acknowledgments}

The authors would like to thank the National Nature Science Foundation of China, China (nos. 51171117, 51003060, and 51101103) and Shenzhen Sci \& Tech research Grants (JCYJ20130329105010137, JC2011042100070A, and ZYC201105170225A) for their financial support.

\section{References}

[1] M. F. Teasley and B. S. Hsiao, "Synthesis and characterization of poly(oxy-1,3-phenylenecarbonyl-1,4-phenylene) and related polymers," Macromolecules, vol. 29, no. 20, pp. 6432-6441, 1996.

[2] P. T. McGrail, "Polyaromatics," Polymer International, vol. 41, no. 2, pp. 103-121, 1996.
[3] P. M. Hergenrother, "The use, design, synthesis, and properties of high performance/high temperature polymers: an overview," High Performance Polymers, vol. 15, no. 1, pp. 3-45, 2003.

[4] P. A. Staniland, "Poly(ether ketone)s," in Comprensive Polymer Science, G. Allen and J. C. Bevington, Eds., vol. 5, pp. 483-497, Pergamon, Oxford, UK, 1989.

[5] K. Tienda, Z. Yu, F. Constandinidis, A. Fortney, W. A. Feld, and E. Fossum, "Poly(arylene ether)s with pendant diphenyl phosphoryl groups: Synthesis, characterization, and thermal properties," Journal of Polymer Science A Polymer Chemistry, vol. 49, no. 13, pp. 2908-2915, 2011.

[6] S. Kaiti and E. Fossum, "Effect of reaction conditions on the molecular weight and polydispersity of linear poly(arylene ether phosphine oxide)s prepared from an $\mathrm{AB}$ monomer," Journal of Polymer Science A: Polymer Chemistry, vol. 44, no. 6, pp. 2099-2106, 2006.

[7] D. P. Bernal, N. Bankey, R. C. Cockayne, and E. Fossum, "Fluoride-terminated hyperbranched poly(arylene ether phosphine oxide)s via nucleophilic aromatic substitution," Journal of Polymer Science, Part A: Polymer Chemistry, vol. 40, no. 10, pp. 1456-1467, 2002.

[8] J. H. Pang, K. Z. Shen, D. F. Ren, S. N. Feng, and Z. H. Jiang, "Polyelectrolyte based on tetra-sulfonated poly(arylene ether)s for direct methanol fuel cell," Journal of Power Sources, vol. 226, pp. 179-185, 2013.

[9] L. Wang, D. Wang, G. Zhu, and J. Li, "Synthesis and properties of highly branched sulfonated poly(arylene ether)s as proton exchange membranes," European Polymer Journal, vol. 47, no. 10, pp. 1985-1993, 2011.

[10] M. Cai, M. Zhu, P. Wang, and C. Song, "Synthesis and properties of novel poly(aryl ether ketone)s containing both diphenyl moiety and amide linkages in the main chains," Polymer, vol. 51, no. 6, pp. 1293-1300, 2010. 
[11] S. M. Mackinnon, T. P. Bender, and Z. Y. Wang, "Poly(aryl ether)s containing o-terphenyl subunits. II. Random poly(ether sulfone)s," Journal of Polymer Science A: Polymer Chemistry, vol. 38, no. 1, pp. 9-17, 2000.

[12] X. Zhao, C. Wang, K. Zhang, Z. Zhou, and M. Zhu, "Soluble poly (aryl ether)s containing naphthalene pendant group: synthesis, characterization and electrospinning," Colloid and Polymer Science, vol. 288, no. 8, pp. 907-914, 2010.

[13] L. B. Krentsel, V. V. Makarova, Y. V. Kudryavtsev et al., "Interchain exchange and interdiffusion in blends of poly(ethylene terephthalate) and poly(ethylene naphthalate)," Polymer Science $A$, vol. 51, no. 11-12, pp. 1241-1248, 2009.

[14] Y. Gao, G. P. Robertson, M. D. Guiver, S. D. Mikhailenko, $\mathrm{X}$. Li, and S. Kaliaguine, "Low-swelling proton-conducting copoly(aryl ether nitrile)s containing naphthalene structure with sulfonic acid groups meta to the ether linkage," Polymer, vol. 47, no. 3, pp. 808-816, 2006.

[15] Q. Zhang, J. Wang, S. Zhang, and S. Li, "Synthesis and alkaline stability of novel cardo poly(aryl ether sulfone)s with pendent quaternary ammonium aliphatic side chains for anion exchange membranes," Polymer, vol. 51, no. 23, pp. 5407-5416, 2010.

[16] M. G. Dhara and S. Banerjee, "Fluorinated high-performance polymers: poly(arylene ether)s and aromatic polyimides containing trifluoromethyl groups," Progress in Polymer Science, vol. 35, no. 8, pp. 1022-1077, 2010.

[17] Q. Zhang, F. Gong, S. Zhang, and S. Li, "Novel side-chaintype cardo poly(aryl ether sulfone) bearing pendant sulfoalkyl groups for proton exchange membranes," Journal of Membrane Science, vol. 367, no. 1-2, pp. 166-173, 2011.

[18] R. Ponnapati, M. J. Felipe, and R. Advincula, "Electropolymerizable terthiophene-terminated poly(aryl ether) dendrimers with naphthalene and perylene cores," Macromolecules, vol. 44, no. 19, pp. 7530-7537, 2011.

[19] X.-F. Li, F. P. V. Paoloni, E. A. Weiber, Z.-H. Jiang, and P. Jannasch, "Fully aromatic ionomers with precisely sequenced sulfonated moieties for enhanced proton conductivity," Macromolecules, vol. 45, no. 3, pp. 1447-1459, 2012.

[20] L. Wang and G. M. Zhu, "Synthesis and characterization of novel poly(aryl ether)s containing naphthyl moieties," Chinese Chemical Letters, vol. 20, no. 8, pp. 965-968, 2009. 

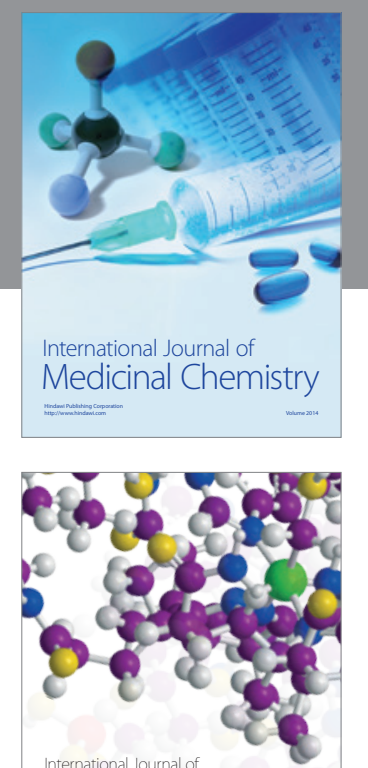

\section{Carbohydrate} Chemistry

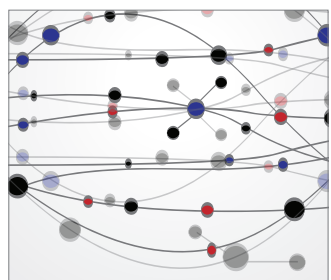

The Scientific World Journal
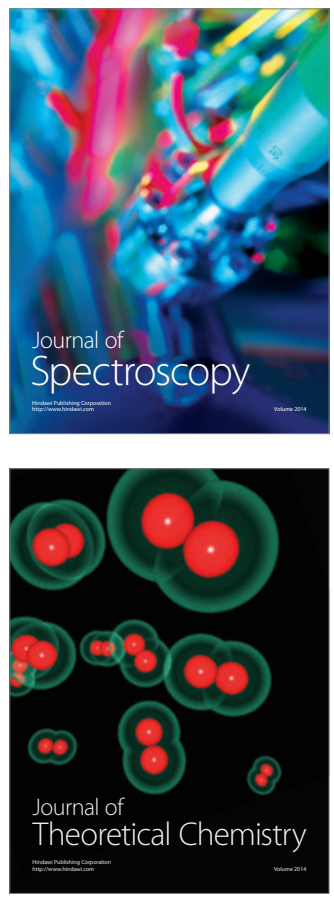
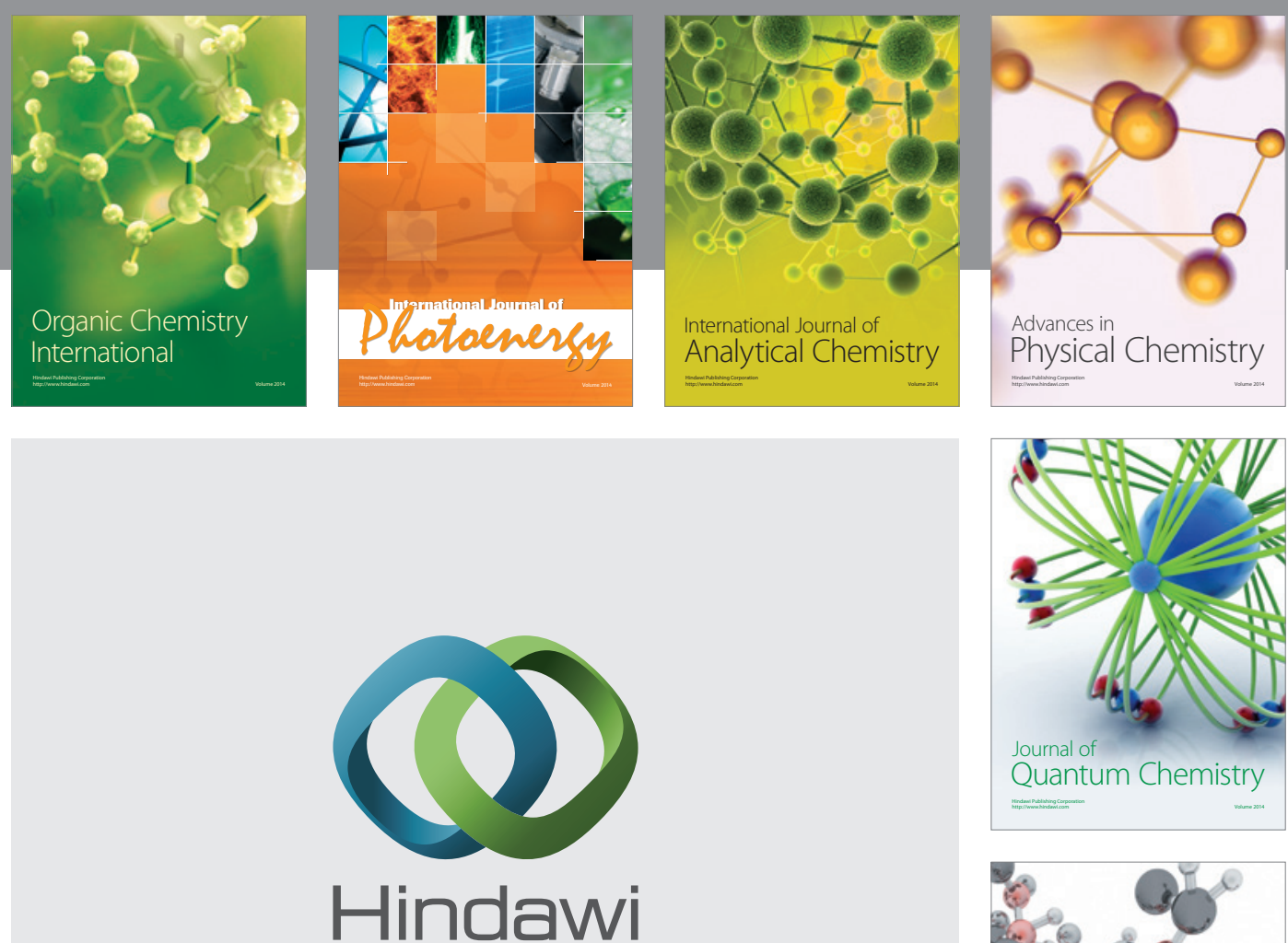

Submit your manuscripts at

http://www.hindawi.com

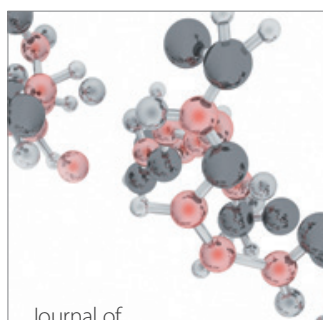

Analytical Methods

in Chemistry

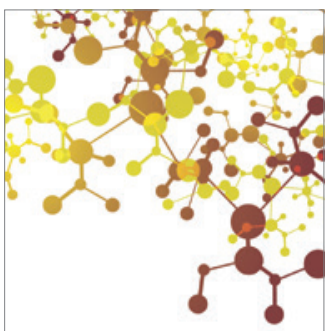

Journal of

Applied Chemistry

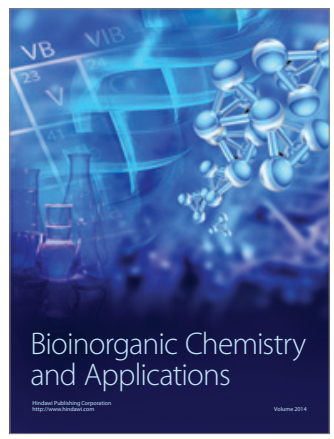

Inorganic Chemistry
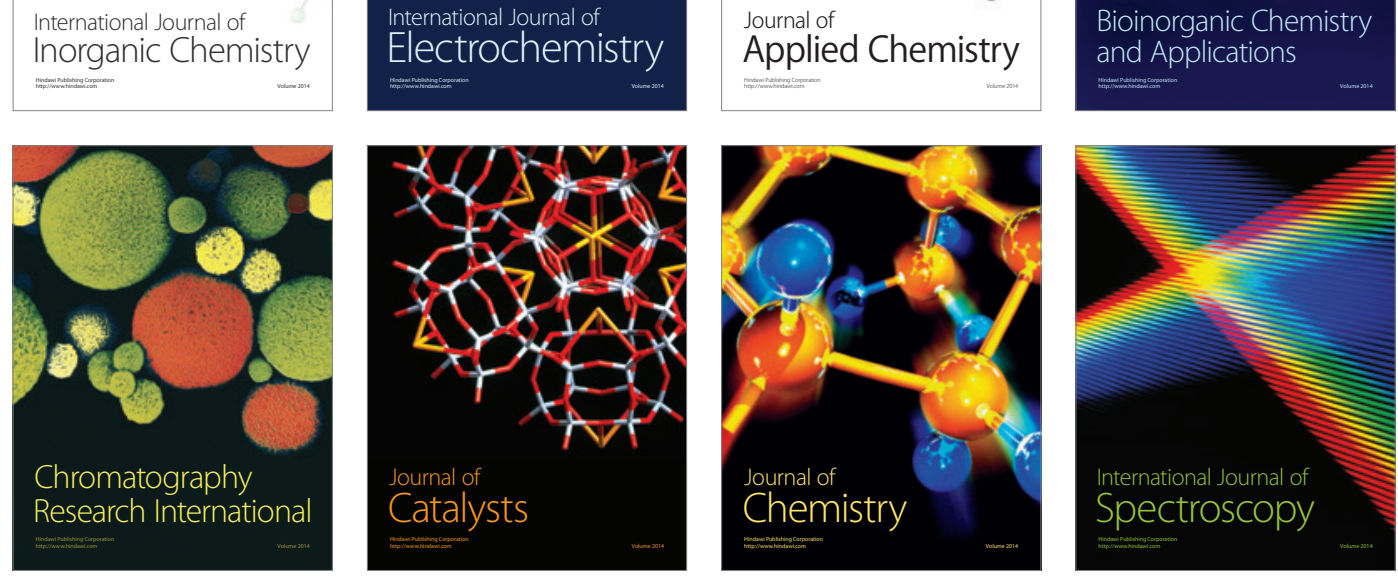